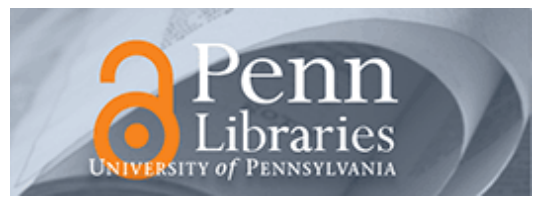

University of Pennsylvania ScholarlyCommons

\title{
Afterword: Ecology and Ideology in Multilingual Classrooms
}

Nancy H. Hornberger

University of Pennsylvania, nancyh@gse.upenn.edu

Follow this and additional works at: https://repository.upenn.edu/gse_pubs

Part of the Bilingual, Multilingual, and Multicultural Education Commons, Educational Methods Commons, and the Social and Philosophical Foundations of Education Commons

\section{Recommended Citation}

Hornberger, N. H. (2003). Afterword: Ecology and Ideology in Multilingual Classrooms. International Journal of Bilingual Education and Bilingualism, 6 (3\&4), 296-302. http://dx.doi.org/10.1080/ 13670050308667787

This paper is posted at ScholarlyCommons. https://repository.upenn.edu/gse_pubs/315

For more information, please contact repository@pobox.upenn.edu. 


\section{Afterword: Ecology and Ideology in Multilingual Classrooms}

\section{Keywords}

language environment, language ecology

\section{Disciplines}

Bilingual, Multilingual, and Multicultural Education | Education | Educational Methods | Social and Philosophical Foundations of Education 
Hornberger, N. (2003). Afterword: Ecology and ideology in multilingual classrooms. International Journal of Bilingual Education and Bilingualism, 6(3\&4), 296-302. http://dx.doi.org/10.1080/13670050308667787

Afterword: Ecology and Ideology in Multilingual Classrooms

by

Nancy H. Hornberger

University of Pennsylvania

To appear in a special issue of the

International Journal of Bilingual Education and Bilingualism

Multilingual Classroom Ecologies: Inter-relationships, Interactions, and Ideologies, edited by Angela Creese and Peter Martin

The present volume represents the first time, to my knowledge, that an ecological approach to multilingual classroom interaction has been foregrounded in a published collection of papers. Elsewhere, I have written about the ecology of language as a metaphor for the ideologies underlying multilingual language policy and practice, in which languages are understood to (1) evolve, grow, change, live, and die in an ecosystem along with other languages (language evolution); (2) interact with their sociopolitical, economic, and cultural environments (language environment); and (3) become endangered if there is inadequate environmental support for them vis-a-vis other languages in the eco-system (language endangerment); and I suggest that central to the language ecology movement, as for other ecology movements, is that it is about not only studying and describing those potential losses, but also counteracting them (Hornberger 2002).

The papers collected here exemplify and elucidate the ecological approach as I have characterized it above. Not only do they describe and study multilingual interaction in the classroom (language evolution), but they also take into account the interrelationships among the languages, their speakers, and other factors in the environment (language environment). Further, the authors seek to uncover underlying ideologies that pervade language choice and language policy, with the goal of proactively pulling apart, and undermining, perceived natural language orders (i.e. counteracting language endangerment).

The multilingual classrooms studied here are located in contexts as diverse and dispersed as village primary schools on the islands of Borneo and Corsica, urban primary schools of the US and the UK, and secondary-level public or community schools of Liverpool, London and Göteborg. The authors offer us a glimpse into a wide array of multilingual classrooms and afford us opportunity to identify similarities and differences across the classrooms and the ecological and ideological relationships they reflect.

Several of the papers are based on rich, in-depth ethnography that affords insider views of, for example: the language and literacy experiences and ideologies of Cambodian girls in Philadelphia or Somali girls in Liverpool; or the marginalization, low status, and dedicated hard work of bilingual support teachers working with Turkish-speaking families in a London secondary school or with Panjabi and Urdu-speaking families in primary schools of Northwest England. Repeatedly as I read the detailed ethnographic 
descriptions and verbatim transcripts of multilingual classroom interaction, I encountered moments that resonated vividly with my own ethnographic observations in multilingual classrooms of Peru, Philadelphia and elsewhere. Peter Martin's description of the frequent problems with pronunciation and understanding he observed on Brunei evoked for me my own observations of the same in classrooms of highland Quechua communities of Puno, Peru (Hornberger 1989). Ellen Skilton-Sylvester's portrayal of Ms. Eakins' culturally relevant pedagogy achieved through congruence of her policies and practices with Khmer ideas of teacher-student relations, even though Khmer language and content are not brought in to the classroom, recalls for me the power of parental expectations for the school to teach the language of power and to do so in the "traditional" way, in both highland Andean indigenous communities and South African black communities (Hornberger 1988, 2002).

Likewise, Alexandra Jaffe's portrayal of the Corsican teacher's emphasis on precision as a characteristic of good narrative echoed my own analysis of Ms. McKinney's good teaching for bilingual literacy with her Southeast Asian 4th graders in Philadelphia (Hornberger 1990). Her description of Corsican children's bilingual practices and identities being mediated by texts and the talk around them as they learn Corsican as their second language, recalled to me my recent visits to Maori immersion classrooms where the teaching of kaupapa Maori 'Maori philosophy', or Maori way of life, is as important or more important than the teaching of Maori language (Hornberger forthcoming).

Other scenes recalled multilingual classrooms I have come to know through my students' ethnographic research. Jo Arthur's example of asymmetrical language choice in the Somali community literacy class, where teachers use Somali and their teen-aged students use English in classroom interaction, brings to mind Korean heritage language classes in the U.S., a context where, as Pak (forthcoming) suggests, MT (mother tongue) is L2 (second language), and teachers and students continuously negotiate and renegotiate their identities and positionings relative to Korean language and culture. Angela Creese's fieldnote about the two Turkish students' rejecting the Turkish bilingual aide's help on classwork after returning to the classroom on the morning of the demonstration recalls for me Cahnmann's description of the shifting terrain of war and reimagination in one bilingual classroom in Puerto Rican Philadelphia and of student and teacher positionings within that terrain (Cahnmann 2001). The scenes described in Angela Creese's and Ellen Skilton-Sylvester's work are after all very familiar to me anyway, since they were both my students too.

In what follows, I recapitulate some highlights from each of the papers, grouped under the three ecological themes mentioned above. In doing so, I hope to point to themes and examples that not only capture the immediate reality of the scenes described herein, but also convey a larger picture of the value and potential of multilingual classroom interaction, both for children's learning and for counteracting language endangerment around the world. I do not pretend to take an unbiased position on either of these goals: I am unabashedly in favor of education for all children in every corner of the world, and likewise support the promotion and development of every language on earth. In my view, the papers here provide, in richly documented detail, considerable grounds for both 
caution and hope as we strive toward those ends.

Language evolution in the multilingual classroom: Positioning, colluding and contesting A number of the papers demonstrate how different languages are positioned differently in the classroom. Skilton-Sylvester speaks in terms of teachers' language policies and ideologies of additive and subtractive bilingualism and shows how one Philadelphia teacher is able to support her Cambodian and other Southeast Asian students' bilingualism even though she doesn't speak Khmer or the other languages; while another teacher, though biliterate in Khmer and English, does not utilize these resources in his classroom and instead seeks to model English use for his pupils at all times (and two other teachers exclude use of Khmer in the classroom). Creese observes that staff and students in one London secondary school position three different groups of Turkish speakers with quite different histories - Turkish mainlanders, Turkish-Cypriot islanders, and Turkish/Kurdish refugees - as one Turkish speaking whole, to the detriment of their understanding why one particular group of (Turkish/Kurdish) students demonstrated against racism in the school. Not just languages, but accents, can be positioned; and not only pupils' language, but teachers' too. Sally Boyd shows, by a series of matched guise investigations and participant observation in six high school classrooms, that judgments (by employers and by pupils) of teachers' foreign-accented Swedish are generalized to judgments of overall Swedish language proficiency, and beyond that to teachers' professional competence, positioning foreign-accented teachers as less competent and less desirable for employment.

Both P. Martin and Jaffe show how texts are used to position languages, teachers, and learners in the multilingual classroom. In the Brunei classroom, English text is authoritative participant and the teacher acts as mediator and guardian of the text, using Bahasa Malay as support. In the Corsican classroom, although the teacher also positions texts as authoritative and herself as mediator, these are mitigated by her emphasis on collective, collaborative production of texts and her commitment to a democratic participation structure which seeks to ensure that all children, not only the most vocal, contribute to the final text product. Furthermore, in her classroom, the two languages used are positioned differently, in that her students' L2 Corsican literacy is always mediated by oral and collective practice, while French literacy is not. An interesting contrast between the Brunei and Corsican cases is that while on Brunei, classroom practice appears to collude with the positioning of a language of wider communication, English, as dominant; in the Corsican case, classroom practice --and Corsican policy-contests the dominant language positioning and seeks to promote Corsican as a language of power.

Then, too, gender and culture play a role in positioning students and teachers in relation to their languages. For example, Deirdre Martin reports that while the Panjabi speaking boys and girls she interviewed at one English primary school clearly recognize English as the language for the classroom but use Panjabi when the teacher is absent, there is a difference between the boys and girls in that the boys contest both class rules and the legitimacy of English during the teacher's absence, while girls are more likely to appropriate the authority, if not the language, of the teacher, attempting to keep order in 
the classroom through the use of Panjabi. Other differences she found in the positioning of Panjabi by boys and girls were that girls, but not boys, have a construct which disengages Panjabi from learning; and that boys, but not girls, construct a tension around speaking Panjabi in front of their English friends.

Here, too, some practices depicted collude with dominant positionings (as above), while others contest them (cf. Martin-Jones \& Heller 1996; Heller \& martin-Jones 2001). In their portrayal of three South Asian bilingual assistants (or aides) in multilingual primary classrooms of Northwest England, Marilyn Martin-Jones and Mukul Saxena highlight the ways in which incorporating cultural funds of knowledge positions the aides in relation to their students. Specifically, they describe how the aides negotiate relationships with students using Urdu and Panjabi; further, their switch to Urdu or Panjabi when addressing individual children is accompanied by a culturally-specific interactional style. In addition, they give several examples of how the aides make references to local people and local community settings and evoke cultural practices that children are familiar with, to the enhancement of the children's learning.

Similarly, Arthur, in her description of community school literacy lessons for Somali teenage girls in Liverpool, provides examples of three literacy events with symbolic meaning (renaming, history of Somali script, Somali language and Islamic culture) and argues that the class contests the marginalization of Somali language and literacy by contributing to the girls' knowledge of their cultural inheritance and giving them a positive experience of the communicative use of Somali. These latter examples, and the example of the first Philadelphia teacher above, contest the traditional positioning of native language and culture outside the classroom, instead bringing them in, as resources for learning.

Language environment and the multilingual classroom: Community funds of knowledge as resource or problem?

Some resourceful mainstream teachers find ways to bring community funds of knowledge into the classroom, but in most cases, that knowledge is closely circumscribed within the school, and even more often, community languages and knowledge are marginalized from the school altogether. Martin-Jones \& Saxena showed us three "resourceful" "bilingual resource" teachers (bilingual assistants or aides) who draw on available communicative resources including languages and literacies, knowledge of local cultural and religious practices (Sikh New Year; non-smoking practices) and of practical skills deployed in everyday life (cooking chapattis); yet we saw too that these aides, and those in Creese's London secondary school, occupy marginalized, low status positions in their schools. Creese also shows us how a student-organized demonstration against racism in the school brings to the fore an institutional school discourse of equal opportunity, which somewhat paradoxically has an adverse effect on how diversity and difference are seen within the school. In this context, community languages are seen, not as a resource, but as a communication hurdle to be surmounted; the headteacher recruits the bilingual aides' knowledge of the Turkish language in getting letters out to Turkish parents about the demonstration, but the goal is not to engage in dialogue with Turkish parents (in Turkish), but to communicate the school's discourse of equal opportunity and 
denial of institutional racism.

In several of the papers, community languages are not only marginalized, but completely absent from the mainstream schools: Panjabi in England (D. Martin), Somali in Liverpool (Arthur), Cambodian in two of the four Philadelphia teachers' classrooms (SkiltonSylvester); and perhaps most strikingly in the case of Brunei, where the three community languages - Dusun, Iban, and Penan -- are totally absent from the classroom, while the children have their lessons in English and Malay, two languages they do not know (P. Martin).

On Corsica, too, children have $50 \%$ of their lessons in Corsican, a language they don't speak when they arrive at school; in this case, though, immersion in the L2 is precisely a case of reclaiming community funds of knowledge in the school, and so fits a different profile from those above. Indeed, the endangered situation of the Corsican language represents a possible, undesirable endpoint of a process in progress in several of the other cases, namely the erosion of community languages by dominant languages of wider communication such as English and French. Arthur notes the incursion of English into Somali homes. D. Martin finds evidence that though Panjabi has both horizontal and vertical legitimacy in the community (since children speak it with their parents and grandparents and because of its association with the Sikh religion), that legitimacy is being questioned in some contexts, for example in young people's failure to attend language and literacy classes at the Temple. Skilton-Sylvester tells us that Ms. Menon emphasizes American language and culture exclusively and feels her students speak their native languages too much at home. In all these cases, community languages are not only absent from the school, but also under threat from dominant languages in the community.

Community schools are, of course, the exception. These schools, such as the one described in Arthur's paper, by definition foster community languages and cultures. Arthur argues that the community school plays a role not only in linguistic reproduction, but also social and cultural reproduction; and further, that the fostering of cultural resources, including literacy, provide an indirect means of promoting (oral) linguistic resources as well.

Finally, these papers give evidence that despite the prohibition or exclusion of community languages from mainstream schools, the languages find their way into the schools nonetheless. D. Martin reports that the Panjabi children she interviewed negotiate their relationships with peers through both languages, and not English only. Skilton-Sylvester reports that, though Mr. Bnom restricts his own use of Khmer in class, he believes it is sometimes valuable for his students to speak to each other in Khmer. P. Martin begins his paper with a telling instance of Bruneian students' collaboratively constructed trilingual translation of a Malay sentence from their lesson into their three community languages.

Language endangerment: Policy, ideology, and re-sourcing 
P. Martin goes on, however, to show that the above instance of trilingual community language use in the classroom runs counter to both Brunei policy and the teacher's normal practices, both of which recognize Malay and English as resources --with English preferred and Malay as support-- while marginalizing Iban, Dusun, or Penan. Similarly, the papers by Martin-Jones \& Saxena, Creese, D. Martin, and Arthur make clear that the use of community languages in British classrooms is at best in the role of support, but not as a preferred resource; the British policy known as "bilingual support" is meant to provide a degree of continuity for the child from community to school, but is an overtly transitional policy, seeking explicitly to avoid bilingual education (Martin-Jones \& Saxena). Skilton-Sylvester makes reference to English-only initiatives in the U.S. which have already undermined decades of bilingual education practice in California and Arizona and threaten to do the same in Massachusetts, and I would add, at the national level under the recent No Child Left Behind Act.

Such policies are undergirded, in turn, by standard language ideologies (S. Boyd). Skilton-Sylvester briefly sketches the ideologies characterizing American linguistic culture: a prevailing language-as-problem orientation, an emphasis on subtractive bilingualism, a questioning of immigrant and refugee rights to native languages, and a narrow view of languages other than English (or whatever dominant language) as useful only for pragmatic, instrumental purposes.

These policies and ideologies, and the power relationships they uphold, are deeply embedded in historical, political, and socioeconomic realities, such as those alluded to in this volume in papers as diverse as Arthur's description of the diasporic Somali community in Liverpool, the longest-standing black community in England, as one "in deep distress," characterized by extreme residential, employment, educational, and social segregation, and an unemployment rate over $70 \%$, at one extreme; the unemployment of foreign-born teachers in Sweden, at the other; and, somewhere in the middle, Creese's story of the community's Turkish language being recruited by the school to undermine (possibly well-founded) accusations of anti-Turkish racism in the school.

The weight of monolingual language education policies, standard language ideologies, and historical forces of racism and poverty is clearly toward endangerment and extinction of community languages, in every case. Facing that reality, these papers yet offer hope that these policies and ideologies can be reversed, at both micro and macro levels.

Boyd suggests that gatekeepers must be made aware of the unwarranted role that judgments of accentedness and language proficiency play in the exclusion of foreigners from qualified employment in Swedish schools; she believes that in many cases the judgments are made "in a spirit of good will" and that gatekeepers are capable of changing their practices, once informed. Certainly, change at the level of individual practice is to be encouraged, and, as the papers here abundantly show, resourceful teachers - and learners -- find ways to subvert monolingual language policies and employ a range of multilingual language practices.

Yet, as Skilton-Sylvester argues, macro level policies and ideologies are so entangled 
with teachers' policies and ideologies at the micro level that educators need to be involved at both levels, if a truly additive perspective is to be possible. She goes on to suggest that engagement at the macro level means working with parents, communities, and policymakers to illustrate the ways that bilingual (or multilingual) instruction benefits students' learning, as well as advocating for adequate funding and professional development for teachers. These are indeed the minimal requirements for a language education policy that would be truly supportive of multilingual learners and community (minority, heritage, ethnic) languages.

The Corsican case offers an example where policy has only recently, after decades of debate and struggle, recognized Corsican language as medium of instruction; and bilingual schooling has been established. Through Jaffe's eyes and ears, we saw how one teacher's practices aimed toward creating symbolic and functional parity between Corsican and French are on the one hand enabled by the broader policy context of Corsican revitalization and on the other challenged by the French-dominant children's everyday life in a community largely lacking an intimate and authentic sense of cultural ownership of the Corsican language.

To meet this challenge at the micro level, the teacher draws on collective, collaborative text production practices that make resources of the children's oral and literacy skills to build their Corsican language and literacy; it is a matter of what Pippa Stein (forthcoming) has called "re-sourcing resources," that is, a process of acknowledging what "historically disadvantaged" students have lost or may be in the process of losing, while simultaneously articulating and recovering the resources they bring to the classroom. There are myriad examples throughout the papers collected here, from the Somali community school which re-sources Somali literacy for a group of teen-age girls, thereby improving their spoken Somali as well, to the Philadelphia teacher who resources her Khmer students' knowledge about Khmer language and culture as input for their life timeline project and for her own learning, to the bilingual aide who re-sources codeswitching as a contextualization cue in addressing individual children in the classroom. It is these concrete and detailed examples of multilingual classroom interaction, and the ideologies they embody, which, for me, offer most hope for the future ecology of languages in our world.

\section{References}

Cahnmann, Melisa. (2001). Shifting Metaphors: Of War and Reimagination in the Bilingual Classroom. Unpublished Ph.D., University of Pennsylvania, Philadelphia. Heller, Monica, \& Martin-Jones, Marilyn (Eds.). (2001). Voices of Authority: Education and Linguistic Difference. Norwood, NJ: Ablex. Hornberger, Nancy H. (1988). Bilingual Education and Language Maintenance: A Southern Peruvian Quechua Case. Berlin: Mouton. Hornberger, Nancy H. (1989). Pupil participation and teacher techniques: Criteria for success in a Peruvian bilingual education program for Quechua children. International 
Journal of the Sociology of Language, 77, 35-53.

Hornberger, Nancy H. (1990). Creating successful learning contexts for bilingual literacy. Teachers College Record, 92(2), 212-229.

Hornberger, Nancy H. (2002). Multilingual language policies and the continua of biliteracy: An ecological approach. Language Policy, 1(1), 27-51.

Hornberger, Nancy H. (forthcoming). Multilingualism-as-resource and the ecology of language: Three cases of language education reform. TESOLANZ.

Martin-Jones, Marilyn, \& Heller, Monica. (1996). Introduction to the special issues on education in multilingual settings: Discourse, identities, and power. Linguistics and Education, 8(1), 3-16.

Pak, Holly R. (forthcoming). When MT is L2: The Korean church school as a context for cultural identity. In N. H. Hornberger (Ed.), Continua of Biliteracy: An Ecological Framework for Educational Policy, Research, and Practice in Multilingual Settings. Clevedon, UK: Multilingual Matters.

Stein, Pippa. (forthcoming). Re-sourcing resources: pedagogy, history and loss in a Johannesburg classroom. In M. Hawkins (Ed.), Social/Cultural Approaches to Language Learning, Teaching, and Teacher Education. Clevedon, UK: Multilingual Matters. 